\title{
Cara ao ermo. Estratexias para o cuestionamento da realidade desde a poesía galega recente
}

\author{
Into the Emptiness. Strategies for Questioning Reality from the \\ Recent Galician Poetry
}

\author{
Antía Marante Arias \\ Universidade de Santiago de Compostela \\ Christian-Albrechts-Universität zu Kiel \\ amarante@ romanistik.uni-kiel.de
}

[recibido 31/10/2014, aceptado 26/01/2015]

\section{RESUMO}

A través da análise dos poemarios Fase de trema de Lorena Souto (Espiral Maior, 2012) e Cero de Oriana Méndez (Galaxia, 2011) proporase unha lectura destes títulos como textos que, por medio do emprego da "metáfora da tolemia", procuran un diálogo intertextual concreto para activar un discurso deconstrutivo -en termos derridianossobre o cuestionamento de realidades, individuais e colectivas, e para artellar novos posicionamentos desde o literario. PALABRAS CHAVE: Poéticas, poesía galega contemporánea, (de)construción, "metáfora da tolemia”, intertextualidade.

\section{RESUMEN}

A través del análisis de los poemarios Fase de trema de Lorena Souto (Espiral Maior, 2012) y Cero de Oriana Méndez (Galaxia, 2011) se propondrá una lectura de estos textos como propuestas que, mediante el empleo de la "metáfora de la locura", buscan un diálogo intertextual concreto para activar un discurso deconstructivo -en términos derridianos-sobre el cuestionamiento de realidades, individuales y colectivas, y para articular nuevos posicionamientos desde lo literario.

PALABRAS CLAVE: Poéticas, poesía gallega contemporánea, (de)construcción, "metáfora de la locura”, intertextualidad.

\begin{abstract}
Through the analysis of the collection of poems Fase de trema by Lorena Souto (Espiral Maior, 2012) and Cero by Oriana Méndez (Galaxia, 2011), a reading of these poems will be suggested as proposals that trough the use of the "Madness metaphor" seek a specific intertextual dialogue in order to boost a deconstructive speech -in Derrida's terms- about reality questioning in order to bring new positions from the literary.
\end{abstract}

KEY wORDS: Poetics, contemporary Galician poetry, (de)construction, "metaphor of Madness", intertextuality.

Marante Arias, A. (2015): "Cara ao ermo. Estratexias para o cuestionamento da realidade desde a poesía galega recente”, Madrygal (Madr.), 18, Núm. Especial: 359-366.

SUMARIO: 1. Contexto. 2. Obxectivos e corpus. 3. Conceptos e tipoloxía dos poemarios. 4. Diálogos intertextuais.

5. Coda. 6. Referencias bibliográficas. 


\section{CONTEXTO}

A nosa proposta xorde como resposta ás preguntas xerais de "cales son as liñas de diálogo que se están a activar hoxe no marco da poesía galega escrita por mulleres" e "cales son os espazos, reais e metafóricos, que nos poemarios se transitan e se conquistan". Tras a nosa análise recente (Marante Arias, no prelo) de poemarios como O pouso do fume de Dores Tembrás (Espiral Maior, 2009), Fase de tre$m a$ de Lorena Souto (Espiral Maior, 2012) ou Raíz de fenda de Berta Dávila (Xerais, 2013), chegou a distinción destes títulos, desde a nosa lectura, como pezas dunha "poética da fenda", ou "poética da ruína", onde a escrita avanzaba cara á reflexión sobre a construción da identidade feminina a partir dun diálogo nostálxico co pasado. Os exercicios memorísticos, nestes títulos, encamiñaríanse a explicitar, no presente, os efectos do paso do tempo -ausencias, territorios ruinosos- para, finalmente, xustificar a definición das falantes líricas en tanto que entidades fendidas, superviventes e superadoras de múltiples embates e reconstrucións.

\section{OBXECTIVOS E CORPUS}

Recollemos, pois, na análise que agora nos ocupa tanto un dos poemarios xa estudados, Fase de trema de Lorena Souto (Espiral Maior, 2012), como o poemario Cero de Oriana Méndez (Galaxia, 2011), para, primeiramente, continuarmos coa delimitación dunha poética da fenda e da ruína onde se sitúan títulos que, malia construírense desde coordenadas ben distintas, comparten o rexistro do tránsito por xeografías baleiras para visualizar poeticamente a necesidade dunha deconstrución que conduza á posterior creación de novos espazos adaptados ás necesidades actuais. En segundo lugar, dilucidarmos como se constrúen dous textos que teñen por obxectivo a revisión das realidades -individuais, colectivas- a través da articulación da voz poética desde a metáfora da tolemia, aquela que permitirá a visión estrañada e fragmentada do contorno. En terceiro lugar, rexistrarmos a rede de referencias intertextuais sobre a cal se constrúen as propostas, isto é, cales son as tradicións literarias nas que se incardinan e coas que dialogan. E finalmente, avanzarmos na reflexión sobre a potencialidade destes discursos como pezas dunha "posmodernidade crítica", en termos de Alfredo Saldaña (1997) ${ }^{1}$, que conduzan á continuar a reflexión, no discurso literario galego, sobre a(s) outra(s) identidade(s) e sociedade(s) posibles.

\section{CONCEPTOS E TIPOLOXÍA DOS POEMARIOS}

Situámonos nas coordenadas reflexivas do filósofo Jacques Derrida e a súa deconstrución ${ }^{2}$ onde, en relación á metafísica, comezan a cuestionarse os modelos pechados, xerárquicos e unívocos para propor unha nova liña de reflexión que distinga novos modelos abertos onde se deconstrúan oposicións duais e xerárquicas e se resitúen, posteriormente, de xeito distinto. Atendemos pois á repercusión do pensamento derridiano en diversas liñas e autores: a revisión da oposición centro/periferia e a consecuente atención ao descentramento de autores como Foucault (1980) ou a lectura poscolonial que propón Spivak (1988); a resposta ao falologocentrismo, artellada desde a crítica feminista por parte de autoras como

\footnotetext{
${ }^{1}$ Citamos a distinción suxerida por Alfredo Saldaña entre "posmodernidade acomodaticia" e "posmodernidade crítica" a través de Helena González que, no seu estudo das achegas de Ana Romaní e Antón Lopo (González: 1999) xa subliñaba a importancia deste matiz e recuperaba a definición de posmodernidade crítica de Saldaña en tanto que liña de creación e pensamento "dinámica, progresista, inconformista e encamiñada a superar as ataduras do presente" (González 1999: 2).

${ }^{2}$ Véxase a entrada dedicada á "deconstrución” do Dicionario de Termos Literarios do Centro Ramón Piñeiro para a Investigación en Humanidades, onde se sistematizan as liñas principais da achega de Derrida, en relación á metafísica da presenza da filosofía occidental, tales como a súa tendencia á revisión dos centros de significado (p. ex. o ser, a verdade), a deconstrución das oposicións de pensamento (p. ex. significado/forma), a eliminación dos límites existentes entre filosofía e literatura ou a reflexión sobre o logocentrismo, entre outras.
} 
Hélène Cixous (Cixous e Clément 1975) ou Luce Irigaray (1977), ou a lectura política do pensamento derridiano activada recentemente por autores como Manuel Asensi, que defende que a deconstrución é "una política que afecta a la totalidad de los campos del saber, una política que toca y afecta a la idea de límite, separación, polaridad, frontera, jerarquía, origen, finalidad, etc.” (Asensi 2014: 11). Neste marco plural a nosa análise explicitará a importancia da revisión de discursos e o emprego do espazo poético como coordenadas abertas ao ensaio ilimitado e ao avance na fixación de propostas alternativas.

Os textos poéticos escollidos para esta lectura artéllanse desde unha nova posición, física e mental, que permite a contemplación distanciada da realidade circundante que ata o momento era a única coñecida. Distinguimos, deste xeito, tanto en Fase de trema como en Cero, un eu poético que sofre as consecuencias da tolemia, enfermidade que resitúa o individuo á marxe relegándoo, tal como veremos, a espazos secundarios de diferente natureza. Mais, asemade, só a través deste desvío é posible unha visión crítica e cuestionadora dos roles, no caso de Souto e das estruturas sociais, no caso de Méndez.

Esta visión distante e distinta que nos interesa tradúcese ademais nos títulos no emprego da linguaxe científica - na liña da ostranénie (estrañamento) da linguaxe proposta polos formalistas rusos ou incluso do distanciamento brechtiano no teatro. Por unha banda, Fase de trema é un diario íntimo pero universal, onde se describen os síntomas de quen no "trema" repara en que a súa percepción de si mesma difire do que é habitual. A través de tres textos extraídos da obra de Klaus Conrad, A esquizofrenia incipiente (1958), este "poemarioprocesual" enfróntanos a tres momentos chave do avance do trastorno. Comprobamos ademais, como, se o psiquiatra alemán bota man do argot teatral -a linguaxe literaria- para explicar na súa obra a evolución da enfermidade, Souto, nun mecanismo inverso, empregará (e manipulará) o material científico para dirixir a lectura da súa proposta poética:
[1] TREMA: Tomada do argot teatral. Algo está para suceder de xeito inminente. Na sensación do febril e o atoparse "á luz" medra unha sorte de tensión interna que arrastra o coñecido cara á tormenta.

Na topoloxía da situación creada polo trema, sempre a mesma constante: Atoparnos nun campo que non podemos abandonar.

(...)

[2] APOFANÍA: Facerse manifesto. Retomar o vivido, cada recordo, a través doutro prisma. Este simple saber o significado, sen ter que preguntar por que se sabe.

O mundo sufriu unha supraordenación de modo semellante ás limaduras de ferro que se "orientan" a un campo magnético.

(...)

[3] CONSOLIDACIÓN: Reestruturación vivencial. Configúrase un campo de significación novo nos espazos inmensos que se abren polas xuntas.

Transformación en si mesmo coma un todo. O camiño que trazan as fendas do plano. (Souto 2013: 14,25 e 37)

En Cero, por outra banda, acóllese, tal como mencionamos no seu momento na recensión á obra, "unha escrita fragmentaria que (...) avanza encarreirada polo pulo dunha voz extremadamente lúcida entre crises de narcolepsia e hiperestesias" (Marante Arias 2011: 91) -“a narcolepsia regresa/calquera pequeno desaxuste provoca que te observe" (Méndez 2011: 37), "en realidade debería mellor dicir que/BHX vive nas miñas hiperestesias" (ibid. 34). Trátase ademais dun poemario que adquire múltiplas fasquías entre elas a dun tratado científico -"o seu verde é magnético/coma o núcleo dos planetas vivos" (ibid. 91)- ou a dun relato de ciencia ficción -"trato de exercer coma un reprodutor/transcribir todo o que BHX me comunica" (ibid. 33), "na periferia do sol observo emanar precipitacións" (ibid. 35). Por esta razón vencéllase fortemente á experimentación xa encetada por Chus Pato que, como apuntaba Helena González -ao respecto do título Charenton (Xerais, 2014)-, supoñía unha "aposta radical de ruptura coa connotación (...) para fundar unha nova linguaxe precisa e denotativa" (González 2005: 201-202). Esta liña de traballo poético demostra como, novamente, segue a ser esencial a construción 
dunha linguaxe única para os novos territorios transitados.

O pulo, na procura de novas coordenadas desde as que enunciar, que se advirte en Cero e Fase de trema é tamén fío invisible que conecta estas poetas máis novas con poetas sobranceiras como a anteriormente mencionada, Chus Pato ou Ana Romaní. As palabras desta última en relación ao seu poemario Estremas (Galaxia, 2010) redundan nunha concepción compartida do poético como espazo á marxe: "Porque o libro ao fin e ao cabo fala diso, do lugar, da posición desde a que construímos os discursos. E de estar fóra, como nun lugar de observación (...) porque é un lugar desde onde se pode observar, e ao mesmo tempo, ter unha visión diferente"3. Nesta liña, o posicionamento que tematicamente evocan Souto ou Méndez pode ser lido como unha proxección da situación real das autoras en varios niveis, que se recoñece: 1) na pertenza a un sistema literario periférico, o galego; 2) na escolla dun xénero axeitadamente definido pola profesora Dolores Vilavedra (2011) como "discreto e pouco mediático", a poesía; 3 ) na atención á posmodernidade; 4) na vontade de avanzar noutros discursos: no caso de Souto, aquel sobre a identidade feminina iniciado na poesía galega a finais dos oitenta e, no caso de Méndez, aquel que canaliza a "asociación de intervención sociocultural" das Redes Escarlatas onde se sitúan, ademais da xa mencionada Chus Pato, poetas como Xavier Cordal ou Gonzalo Hermo, entre outros.

Non obstante, describir o posicionamento deste xeito resulta limitador. Se atendemos á reflexión sobre a deconstrución da dialéctica centro/periferia (marxe) comprobaremos como, tanto a pertenza ao sistema literario, como a escolla xenérica, a adscrición a un movemento alternativo ou a visibilización dos outros discursos poden valorarse per se para concluír que as poetas optan por situarse, coas súas achegas, en espazos autónomos, isto é, non necesariamente definidos en relación a un centro preexistente ao que se lle recoñece lexitimidade exclusiva.

\section{DIÁLOGOS INTERTEXTUAIS}

Como apuntamos, o emprego da metáfora da tolemia é a estratexia textual escollida polas poetas para construír unha poesía en chave crítica e subversiva. Esta escolla, ademais, implica un diálogo directo con dúas tradicións literarias concretas no caso de Souto, co xénero gótico a través de autoras decimonónicas anglófonas -tamén coas súas biografías- e, no caso de Méndez, cos xéneros da épica e da ciencia ficción.

Cómpre unha análise polo miúdo das redes textuais presentes nos poemarios, mais subliñaremos polo de agora a forte tendencia á ficcionalización que existe nas propostas - característica xa apuntada por Helena González (2008: 41) na súa análise de textos de Chus Pato, $m$-Talá (Xerais, 2000) e Charenton (Xerais, 2004), ou da anterior obra de Oriana Méndez, As derradeiras conversas co Capitán Kraft (Galaxia, 2007). O diálogo que establecen as poetas con outras tradicións e sistemas literarios serviranos, ademais, para encetar, no posible, a nosa futura reflexión sobre estes textos tendo en conta as cuestións seguintes: en que tradicións se recoñecen?, que lles ofrecen estes xéneros?, cal é o alcance dos discursos poéticos que xorden a partir destes vencellos?

Cero comeza coa cita extraída da novela L'angelo custode da escritora suíza Fleur Jaeggy. O "eloxio á loucura" que Jaeggy pon en boca dunha nena que conversa con Jane e Rachel, protagonistas da obra, -"eu soñaba con ser tola, grandiosamente tola, coma un raio"-conecta coa aposta do poemario de Méndez por un eu poético "cuxas chaves de percepción do real distan das ordinarias" (Marante Arias 2011: 91) e que se sitúa nun grupo de percepción desviada -"Podo pensar que as persoas coma min comparten/ o sentido da vida:/unha continuidade de alucinacións/feraces" (Méndez 2011: 25).

\footnotetext{
${ }^{3}$ Palabras da autora extraídas da conversa coa xornalista Ana Salgado (Salgado 2011: 14-17).
} 
A tendencia á ficcionalización apuntada tradúcese en Cero nun diálogo alucinatorio do eu poético co personaxe feminino $\mathrm{BHX}^{1}$ :

"nos primeiros contactos entendín que BHX/ era unha muller", "a voz da que falo pode introducirse nas luces/pero non é unha voz", "pode aparecer no medio da película", "descoñezo se os outros habitantes se decatan/si sei que, en caso de facelo, manteñen silencio/arredor deste feito desconcertante". (Méndez 2011: 33)

Un diálogo que ademais conecta co xogo que se desenvolve na novela de Jaeggy citada, onde tanto os límites espaciais como os límites persoais entre as idénticas nenas Jane e Rachel sempre están difusos -"por lo tanto, hermana, permanezcamos entre nuestras cuatro paredes, para no salirnos del modelo, ajustémonos la una a la otra y volvamos sobre nuestros pasos" (Jaeggy 2010: 97). As múltiplas interpretacións que xorden tras a lectura de textos como o de Jaeggy ou Méndez chaman a atención sobre a debilidade da propia natureza das obras que, ao explotar como estratexias literarias a percepción distorsionada ou o fragmentario, poden multiplicar a súa significación, desbotar as correspondencias unívocas e, polo tanto, a perfecta cohesión.

En definitiva, a metáfora da tolemia desenvólvese en Cero nas lindes da poesía narrativa -lerase tamén a obra como exemplo claro de epización ${ }^{2}-$ e dun xénero híbrido entre a ciencia ficción e a épica ${ }^{2}$, onde o eu poético e o seu coadxuvante inician a súa partida desde un territorio oprimido para garantir a súa supervivencia -"ti e mais eu na profundidade dun número/calculando as saídas" (Méndez 2011: 14) - e avanzan nunha misión "encargada pola familia" (ibid. 69) ata chegar a Mudmax nun transportador, toponimia ambivalente que volve facernos dubidar sobre a súa existencia fóra da mente de quen enuncia - "galerías encarnadas das nosas demencias" (ibid. 76).

Fase de trema ademais de artellarse, como comentamos, a partir das referencias ás fases da esquizofrenia distinguidas por Conrad, rescata un diálogo con autoras decimonónicas entre as que destaca, moi especialmente, a norteamericana Charlotte Perkins Gilman co seu relato "The Yellow Wallpaper" ("El papel de pared pintado de amarillo", 2012 [1892]). Neste conto a autora describe o retiro, entendido como cura por prescrición médica, que unha muller escritora debe seguir, aconsellada polo seu marido doutor, para recuperarse dun estado nervioso. Souto recupera a tensión, e posterior tenebrismo, do relato de Perkins, onde se rexistra a involución da muller que, no marco do cuarto onde está recluída, no canto de recuperarse, comeza a sofrer alucinacións. Así, a cita de Perkins no poemario -"cando parece que o conseguen, o debuxo estrangúlaas e vólveas boca arriba, deixándoas cos ollos en branco" (Souto 2012: 28)- debe ser lida como fase final do proceso de empeoramento da protagonista de Perkins:

Este papel tiene una peculiaridad muy marcada, algo que por lo visto sólonoto yo: que cambia con la luz (...) El dibujo principal se mueve, efectivamente, iy no me extraña! ¡Lo sacude la mujer de detrás! A veces pienso que detrás hay varias mujeres: otras veces que sólo hay una, que se arrastra a toda velocidad y que el hecho de arrastrarse lo sacude todo. (Perkins Gillman 2012 [1892]: 80)

En Fase de trema o diálogo ficcional sitúase nos límites dun relato gótico: "canicas de aire correndo polas tubaxes/preséntanme

\footnotetext{
${ }^{4} \mathrm{O}$ nome deste personaxe relembra a HRG, figura evocada por Chus Pato en Hordas de escritura (Xerais, 2008).

${ }^{5}$ Tal como se apunta na entrada "Epización” do Dicionario de Termos Literarios, os textos - de autores como, por exemplo, Ezra Pound (The Cantos) ou, no eido galego, X. L. Méndez Ferrín (Estirpe) (estudado desde esta noción por Iris Cochón Otero)- que participan desta tendencia caracterízanse, entre outros elementos, pola "incorporación de estruturas míticas, aparición de recursos da narratividade e da oralidade, rehabilitación da composición episódica, procura dunha impostación enunciativa de carácter presentativo, ritual e pseudoescénico (...)".

${ }^{6}$ Resulta tamén suxestiva a lectura do poemario como espazo de confluencia de temporalidades e como perpetuación do discurso épico na ciencia ficción.
} 
os pasos dela/abandonando o faiado" (Souto 2012: 39). Souto explota o lugar común deste "aparente diálogo" ou "monólogo interior alucinado" -"e falamos con palabras escuras/ que aprendemos nas novelas góticas" (Souto 2012: 39)- e a presenza do tropo da pantasma -"atando o seu pelo/ longuísimo e cano" (id.)para conectar, por exemplo, coa última sección do libro de Jane Rhys, Ancho mar de los sargazos (1966), onde a tola Antoinette Cosway, primeira señora de Rochester, xa está recluída no ático de Thornfield Hall -relembramos que Rhys narra a prehistoria desta muller, procedente das Antillas, que aparecía no universo literario da Jane Eyre de Charlotte Brontë-: "Entonces lo vi, el fantasma de la mujer. La mujer con el largo cabello suelto. Estaba rodeada por un marco dorado, pero la conocía (Rhys 1998: 186).

Leremos, pois, estes exercicios de literatura na literatura, isto é, dos vencellos do eu de Fase de trema en conexión con aquelas "tolas dos faiados", tal como as denominaron Sandra M. Gilbert e Susan Gubar (1998) -a muller recluída no cuarto de empapelado en amarelo que describe Perkins, pero tamén a tola Antoinette Cosway en Thornfield Park-, elixidas polas escritoras como vehículo de transimisión das outras percepcións, como chamada de atención ás intrahistorias cuxa verbalización non podía ser canalizada a través de vías lingüísticas e literarias ao uso.

\section{CODA}

Esta sucinta lectura dos títulos permítenos encetar unha liña de traballo que ten por obxecto analizar algunhas mostras da poesía galega máis recente como espazos de reflexión que visibilizan múltiples percepcións da realidade e responden ás dialécticas centro e periferia desde a necesidade da súa deconstrución -na liña de Derrida ou Foucault apuntadatendo en conta a súa natureza de construtos, históricos e culturais e, polo tanto, destacando a posibilidade da súa revisión.

Nestas liñas rastrexamos, pois, as estratexias textuais empregadas polas autoras -ficcionalización, diálogos/monólogos alucinatorios, referencias á tolemia- e as tradicións coas que dialogan -novela gótica, ciencia ficción, épica, epización- para comprobar como, a partir dun diálogo directo con liñas de creación xa consolidadas na literatura universal, as poetas encetan un traballo de revisión para definir os seus espazos de forma autónoma, sen recolocacións ou conquistas, en relación ás súas novas necesidades reivindicativas e discursivas.

A nosa análise sitúase no marco da atención ao indecidible que activou Derrida, tal e como subliñou Asensi, "se podría decir que la obra de Derrida ha consistido desde los años sesenta hasta la actualidad en una producción de indecidibles (archi-escritura, diseminación, huella, parergon, différance, ruina, ceniza (...)" (Asensi 2014: 19). Do conxunto destes indecidibles, ou terminoloxías abertas, destacamos, por ser do noso interese, a "pegada", a "ruína" ou o "espectro".

Se a pegada do pasado nos interesou á hora de definir unha "poética da fenda (e da ruína)", interésannos nesta ocasión os mecanismos empregados polas poetas para literaturizar o irracional, liminal e espectral e, por tanto, a visión outra, ben a través da figura marxinalizada dun suxeito feminino enfermo, ben a través dunha figura receptora de revelacións provintes de realidades (e coordenadas) afastadas.

Concluímos chamando a atención sobre a importancia dunha lectura polo miúdo da rede textual que Souto e Méndez manexan -dun modo eminentemente narrativo- para construír os seus universos poéticos subversivos e expansivos. O emprego literario da (dura) realidade da tolemia, cuxa potencialidade, como advertimos, foi rentabilizada por moitas autoras para transmitir discursos marxinados, antóllase novamente unha estratexia para actualizar a reflexión sobre posicionamentos, coordenadas e espazos.

Tras a voráxine chega a calma -"E todo cae por fin" (Souto 2012: 46), "Batemos por fin cos nosos corpos en Mudmax" (Méndez 2011: 75)- e neses espazos ermos e baleiros que presentan as poetas pouco queda xa das paredes, dos faiados, dos cuartos escuros, quizais para demostrar como, novamente, a poesía está sempre un paso máis adiante da realidade. 


\section{REFERENCIAS BIBLIOGRÁFICAS}

\section{BIBLIOGRAFÍA PRIMARIA}

JAEGGY, Fleur (2010 [1971]): El ángel de la guarda. Barcelona: Tusquets.

MÉNDEZ, Oriana (2011): Cero. Vigo: Galaxia.

Perkins Gilman, Charlotte (2012 [1892]): El papel pintado de amarillo (The yellow wallpaper). Zaragoza: Contraseña.

RHYs, Jane (1998 [1966]): Ancho mar de los sargazos. Madrid: Anagrama.

Souto, Lorena (2012): Fase de trema. Oleiros: Espiral Maior.

\section{BIBLIOGRAFÍA SECUNDARIA}

AsEnSI, Manuel (2004): ¿Qué es la deconstrucción de Jacques Derrida?, Visions de L'Escola Tècnica Superior d'Arquitectura 3, pp. 11-19.

Cixous, Hélène e Catherine Clément (1975): La jeune née. Paris: U.G.E.

Cochón, Iris (1998): “Dicción, contradicción e nación: a incorporación do mundo no discurso poético último", Grial. Revista galega de cultura 140, pp. 717-730.

FouCault, Michel (1980): Microfísica del poder. Madrid: La Piqueta.

Gilbert, Sandra M. e Susan Gubar (1998): La loca del desván: La escritora y la imaginación literaria del siglo XXI. Madrid: Cátedra.

GonZÁlez FernándeZ, Helena (1999-2000): “Tres argumentos para di/versificar as identidades de xénero: Arden, Pronomes e Lob*', en Lectora. Revista de Dones i Textualitat, pp. 5-6, 8995 (reed. en poesíagalega.org. Arquivo de poéticas contemporáneas na cultura).

(2005): Reseña de Charenton de Chus Pato, Anuario de Estudos Literarios Galegos 201, pp. 201-202.

(2008): "Encrucijadas identitarias gallegas y el laboratorio del lenguaje", en M. Palacios González e H. González Fernández (eds.), Palabras extremas: Escritoras gallegas e irlandesas de hoy. Oleiros (A Coruña): Netbiblo, pp. 29-47.

IrIGARAY, Luce (1977): Ce sexe qui n'en est pas un. Paris: Éditions de Minuit.

Marante Arias, Antía (2009): "Dores Tembrás: calígrafa y fotógrafa", Caravansari. Revista de Poesía Contemporánea en Lenguas Peninsulares IV, pp. 9-12.

(2011): "Poesía feroz dos espazos ermos", Grial. Revista galega de cultura 191, pp. 90-91.

(2012): "Suma de detonacións a pequena escala, Grial. Revista galega de cultura 195, pp. $92-94$.

(2014): “As palabras baixo o subsolo", Grial. Revista galega de cultura 201, pp. 72-73.

(no prelo): "Memoria, infancia, fenda. Un achegamento á construción da identidade nas voces poéticas femininas máis recentes", Itinerarios (no prelo).

Saldaña, Alfredo (1997). El poder de la mirada. Acerca de la poesía española posmoderna. Valencia: Episteme.

SAlgado, Ana (2011): "Estremas fala da usurpación dos discursos, da linguaxe, dos corpos", Protexta 17, pp. 14-17. 
SPIVAK, Gayatri Chakavortri (1988): Can the subalterns speak?: Marxism and the Interpretation of Culture (eds. C. Nelson e L. Grossberg). Illinois: University of Illinois Press, pp. 271-313.

VilaVedra, Dolores (2011): “Tempo de devalar”, El País 28-10-2011.

\section{RECURSOS ONLINE}

Casas, Arturo (ed.): Poesíagalega.org. Arquivo de poéticas contemporáneas na cultura. Base de datos e repositorio dixital (http://www.poesíagalega.org).

EQuiPo Glifo (dir.): Dicionario de termos literarios (DiTerLi). Santiago de Compostela: Centro Ramón Piñeiro para a Investigación en Humanidades (http://www.cirp.es/pls/bdo2/ $\underline{\mathrm{f}} \mathrm{p}=\mathrm{DITERLI})$.

Losada Soler, Elena (coord.): Lletra de dona. Barcelona: Centre de Dona i Literatura da Universitat de Barcelona (http://www.ub.edu/cdona/lletradedona). 